\title{
CATWALK ELETRÔNICO: ENQUADRAMENTOS DA MODA NO GNT FASHION $^{1}$
}

\author{
CATWALK ELECTRÓNICO: LOS MARCOS DE LA MODA EN GNT FASHION
}

ELETRONIC CATWALK: FASHION FRAMES IN GNT FASHION

\author{
Fernada Martineli \\ UFRJ \\ nandamartineli@yahoo.com.br \\ Liziane Guazina \\ $\mathrm{UnB}$ \\ liziane.g@uol.com.br
}

\section{Resumo}

O artigo analisa a cobertura do programa de TV GNT Fashion sobre as semanas de moda do Rio de Janeiro e de São Paulo para o outono/inverno 2011. Utilizamos o conceito de enquadramento, a partir de Goffman e outros autores, para pensar a relação da produção midiática com atores sociais em diferentes níveis: estilistas e marcas, comentaristas 'especialistas', celebridades, entrevistados e a audiência. A análise se concentra na construção de sentido sobre a moda brasileira, suas especificidades e sua representação social.

Palavras-chave: Moda. Mídia. Consumo. Cultura.

\section{Resumen}

Este artículo analiza la cobertura del programa de televisión GNT Fashion durante el evento conocido como las semanas de la moda en Río de Janeiro y São Paulo para la temporada otoño/invierno de 2011. Utilizamos el concepto de encuadramiento, de Goffman y otros, para pensar la relación entre la producción de los medios de comunicación con los actores sociales en diferentes niveles: los diseñadores y las marcas, los expertos comentaristas, celebridades, entrevistados y el público. El análisis se centra en la construcción del significado de la moda brasileira, sus referencias y representaciones sociales.

Palabras-clave: Moda. Medios de Comunicación. Consumo. Cultura.

\footnotetext{
${ }^{1}$ Este artigo é uma versão alterada do trabalho apresentado no GT “Antropologia da Comunicação" na IX Reunião de Antropologia do Mercosul, realizada de 10 a 13 de julho de 2011 em Curitiba-PR.
} 


\begin{abstract}
This paper analyzes the coverage of the TV show GNT Fashion during the event known as fashion weeks in Rio de Janeiro and São Paulo for the autumn/winter 2011. We use the concept of framing from Goffman and other authors, to analyze the relationship between the media production with the social actors at different levels: designers and brands, 'experts', celebrities, interviewees and the audience. The analysis focuses on the construction of meaning of what is considered the Brazilian style, its characteristics and social representation.
\end{abstract}

Keywords: Fashion. Media. Consumption. Culture.

\begin{abstract}
"But, my dear, it's perfectly charming!" Rose Shaw said, looking her up and down with that little satirical pucker of the lips which she expected - Rose herself being dressed in the height of the fashion, precisely like everybody else, always.
\end{abstract}

- Virginia Woolf, The New Dress (1927)

\title{
1. O catwalk ${ }^{2}$
}

Está escuro e chove dentro do Pavilhão. "Chove muito", comenta o editor de moda Paulo Martinez. Homens e mulheres seguem o mesmo percurso, como se estivessem executando uma coreografia. "Michelle Provensi acabou de passar. Olha, estão todos encharcados", observa a jornalista Lilian Pacce.

Os corpos caminham sobre o espelho d'água que se forma no chão pela chuva criada artificialmente e que reflete esses mesmos corpos, cores e cortes em formas distorcidas. Formas que desfilarão em outros corpos e por outros caminhos, no catwalk das ruas no inverno brasileiro.

Este é o cenário do desfile da marca Cavalera, que aconteceu nas instalações da Bienal de Arte na capital paulista, encerrou a edição de inverno do São Paulo Fashion Week em 2011 e foi transmitido ao vivo pelo programa de TV GNT Fashion, que integra a grade de programação do canal pago GNT.

\footnotetext{
${ }^{2} \mathrm{O}$ termo catwalk (passarela, em inglês) faz referência, no contexto deste artigo, tanto à transmissão de desfiles de moda via novas tecnologias - especialmente via canal pago de televisão (catwalk eletrônico) -, quanto ao percurso analítico aqui empreendido.
} 
O tema do referido desfile foi "República Federativa Cavalera", e elementos como brasões e bandeiras - do Brasil e do estado de São Paulo - eram uma constante nas roupas. Tudo devidamente estilizado, como bem observa Pacce:

Aí é um pedaço da grade da bandeira de São Paulo em preto e branco. Eles [os estilistas da marca, Fabiano Grassi e Igor de Barros] vão trabalhando essa imagem ao longo do desfile, misturando a bandeira de São Paulo com o brasão da República, porque a idéia é fazer uma república, uma nova república.

Essa "nova república", no entanto, não tem o mesmo significado político da Nova República que se instala como forma de governo e marca o fim da ditadura militar no Brasil. A "República Federativa Cavalera" é, antes, mais estética que política, embora seja também reveladora de aspectos que estruturam a moda tanto como um sistema mais amplo, nas suas dimensões de produção, trabalho e consumo, quanto no plano da vida íntima e cotidiana.

É nesse sentido que este artigo se propõe a pensar a moda para além da sua trivialidade. A proposta é analisar a cobertura do GNT Fashion sobre as edições de outono/inverno de 2011 das duas principais semanas de moda do país: o Fashion Rio e o São Paulo Fashion Week. O objetivo é investigar de que maneira o programa enquadra as narrativas de alguns desfiles, em particular, e dos eventos, de uma forma mais geral, em termos de cultura, consumo, identidade, comportamento e estilo de vida.

A partir desta delimitação, vamos refletir sobre a relação desta produção midiática com outros atores sociais em diferentes níveis: estilistas, marcas, comentaristas "especialistas", celebridades, entrevistados e a audiência, que interage, ao vivo, via Twitter. A análise se concentra na construção de sentido sobre a moda brasileira, suas especificidades, referências criativas, formas organizativas e sua representação sociocultural. Nesse trajeto, temas tão heterogêneos como moda, mídia, juventude, política e arte, entre outros, se entrelaçam e complexificam o objeto.

$\mathrm{O}$ percurso analítico começa com algumas pistas teórico-metodológicas que orientaram a problemática deste estudo. Em seguida, o foco se detém na organização do programa durante as semanas de moda, explorando sua estrutura discursiva e de produção televisiva. Os enquadramentos são apresentados na sequência, sendo que o primeiro, intitulado "As bandeiras da Cavalera", trata do desfile de uma marca de roupas que adota 
como linha criativa e conceitual a associação de ideais e valores da juventude vinculados a uma experiência política muito particular. "Explicadores da moda: o dourado é o novo preto" é o segundo enquadramento, que se detém em analisar como a audiência é pensada e/ou retratada pelos apresentadores do GNT Fashion, ao mesmo tempo em que problematiza o papel dos comentadores/especialistas e jornalistas. O terceiro enquadramento, "Thinking outside the box: moda como arte" é uma reflexão sobre as relações entre moda e arte e o próprio trabalho do estilista como autor. Finalmente, nas considerações finais - ou "encerramento do desfile" - apresentamos reflexões mais amplas sobre a moda relacionando aos mundos do trabalho, produção e consumo.

\section{Algumas pistas teórico-metodológicas}

Antes de iniciar nosso próprio catwalk, vamos definir o percurso teórico-metodológico que guia os passos na análise do objeto. Neste estudo exploratório, não nos detivemos em estabelecer categorias classificatórias fechadas, mas seguir o curso do olhar crítico para compreender o universo particular da moda e suas múltiplas possibilidades de construção de sentidos, a partir de alguns conceitos-chave. O primeiro deles é o de enquadramento, utilizado aqui conforme proposto por Goffman (1986). Em sua definição, o autor diz que enquadramentos são "princípios de organização que governam os acontecimentos - pelo menos os sociais - e o nosso envolvimento subjetivo neles" (p. 10-11). Estes princípios seriam, portanto, os norteadores - de maneira inerente - de nosso modo de ver e pensar o mundo.

No contexto atual das pesquisas brasileiras que utilizam o enquadramento como conceito relevante, a maior parte dos estudos, no campo da comunicação, tem se dedicado a desvendar as relações entre a mídia e a política. Estes estudos vão desde pesquisas sobre a construção de enquadramentos de fontes na relação com os jornalistas, passando por pesquisas sobre audiência, organizações de mídia, textos noticiosos, e até sobre culturas nas quais os enquadramentos são construídos (GUAZINA, 2001). Este último aspecto é relevante aqui, uma vez que a cultura é o tecido fundamental onde se tecem - estabelecem e se (re)constroem valores e identidades. 
Aldé (2004), por exemplo, em estudo de recepção sobre a construção dos valores da política a partir do conteúdo jornalístico, aponta que os enquadramentos são estruturas cognitivas que organizam o pensamento, compostas de crenças, atitudes, valores e preferências. Exatamente por se constituírem como construções culturais, podem se realizar nas narrativas jornalísticas, fazendo a conexão entre os valores e explicações estruturais (naquele caso, sobre a política) e a realidade cotidiana das pessoas (p. 47).

Assim, ao enquadrar, os narradores (jornalistas, apresentadores, comentaristas, etc) definem pontos de vista e hierarquizam informações, selecionando algumas em detrimento de outras. Deste modo, o resultado de qualquer trabalho com características jornalísticas é eminentemente enquadrado, isto é, organizado a partir de princípios culturais compartilhados que estão na base da decisão de selecionar (GUAZINA, 2011).

Um aspecto essencial do conceito de enquadramento é o de seleção, a partir da ênfase em determinados aspectos e da omissão de outros. Quando uma informação é salientada em um texto (e aqui considera-se texto inclusive as imagens), ela se torna mais significativa e memorável para a audiência, indicando um modelo de interpretação dominante, isto é, uma orientação de interpretação a ser seguida (ENTMAN,1993).

Ao mesmo tempo, o conceito de fato social total (MAUSS, 2007) emergiu como uma abordagem complementar que guiou nosso olhar a partir do reconhecimento da "mistura" como uma categoria nativa. No contexto do objeto investigado "mistura" adquire diversos significados, tanto em função de um uso recorrente e coloquial na fala das fontes de pesquisa, quanto como conceito das ciências sociais, útil para pensar essas mesmas falas no enquadramento do GNT Fashion e em perspectiva com as semanas de moda e o próprio universo social mais amplo.

Nesse sentido, Becker (2007) foi uma inspiração para incorporar dimensões analíticas que eventualmente poderiam se constituir como um impasse entre o interacionismo simbólico e o fato social total, mas que aqui se estruturam como um diálogo metodológico que incorpora a reflexividade externa ao objeto na análise da ação social.

Enquanto o enquadramento privilegia as análises de contextos sociais bem delimitados e definidos pelo pesquisador, o conceito de fato social total pressupõe um recorte analítico em função de situações pertinentes ao próprio objeto - ou seja, o ponto de observação não é fixo nem isolado, de tal forma que o pesquisador transita entre diferentes níveis do fato (entre o 
micro e o macro, o mais específico e o mais estrutural) para apreender a complexidade do objeto. Becker viabiliza esse diálogo quando afirma ser possível compreender melhor as interações sociais buscando premissas que não estão explícitas porque foram silenciadas, mas são amplas e recorrentes na experiência de vida cotidiana (2008, p. 193). O que o sociólogo sugere é "trazer o que foi omitido de volta para a análise" (ibidem). É nesse horizonte que este estudo articula as ferramentas teóricas e se caracteriza por uma heterogeneidade de vozes, circunstâncias e situações (MARTINELI, 2011). Este é, portanto, um trabalho baseado em experiências de compreensão.

Para fins deste estudo exploratório, consideramos o GNT Fashion como um programa jornalístico de televisão específico sobre moda. E como tal, ele foi objeto de nossos apontamentos predominantemente a partir do conceito de enquadramento, e transversalmente considerando a narrativa do programa nos enquadramentos analisados em perspectiva com contextos socioculturais mais amplos.

A seguir, vamos mostrar algumas das principais características estruturais dos programas para contextualizar o universo analisado.

\section{A organização do programa nas semanas de moda}

As duas edições do programa GNT Fashion - Rio de Janeiro e São Paulo - foram ao ar, ao vivo, nos dias 12 de janeiro de 2011 e 2 de fevereiro de 2011, respectivamente, pelo canal da TV a cabo GNT. O programa dedicado à cobertura das tendências de moda apresentadas pelas marcas no Rio de Janeiro (entre elas, a do estilista pernambucano Melk ZDa, British Colony e a Maria Bonita Extra) teve 40 minutos de duração. Já o programa dedicado às marcas presentes no evento de São Paulo (Cavalera, André Lima e Colcci, por exemplo) durou 57 minutos e 16 segundos.

Em ambas as edições, a jornalista Lilian Pacce e a ex-modelo Mariana Weickert apresentavam e entrevistavam (a primeira no estúdio e a segunda no local dos eventos), e um grupo de especialistas se revezava em comentar as tendências mostradas nos desfiles das duas semanas de moda outono-inverno 2011. Também foram realizadas entrevistas temáticas gravadas com os participantes das Fashion Weeks que abordavam, por exemplo, os usos de 
novas tecnologias e ferramentas de comunicação como Twitter, Facebook e aplicativos para celular.

No programa dedicado aos desfiles das marcas do Rio de Janeiro, participaram como comentaristas fixos no estúdio montado pelo canal no local dos desfiles, o cantor Léo Jaime e a stylist Flavia Pommianosky. Também foi ouvida a estilista Ana Magalhães, da marca Maria Bonita Extra, que comentou o seu próprio trabalho. Além disso, foram entrevistadas celebridades (especialmente atores e atrizes da Rede Globo como Tuca Andrada, Helena Ranaldi, Cleo Pires, Camila Pitanga, Bruno Gagliasso, Júlia Lemertz, entre outros), e especialistas do mundo da moda, como maquiadores, produtores, modelos, jornalistas especializados, assessores de imprensa e editores.

No programa sobre as tendências de moda das marcas em São Paulo, participaram como comentaristas fixos o estilista André Lima, o editor de moda Paulo Martinez e o maquiador Marcos Costa. Assim como na edição do Fashion Rio, foram entrevistados especialistas do universo fashion, com especial tempo dedicado à modelo Gisele Bundchen, que falou sobre o lançamento da sua própria marca de produtos de beleza, comentou uma polêmica declaração sua sobre o uso de protetor solar ${ }^{3}$ e respondeu a perguntas de telespectadoras enviadas via Twitter a respeito de uma possível mudança para o Brasil.

As duas edições especiais do GNT Fashion também foram caracterizadas pela busca de uma associação com as novas tecnologias e redes sociais virtuais mencionadas acima, especialmente o uso do Twitter, e de aplicativos para smartphones, como o Iphone, e tablets, como o Ipad. Essa ênfase pode ser notada no programa de São Paulo, por exemplo. Boa parte do tempo da edição foi dedicada às entrevistas sobre o uso de aplicativos pelos fashionistas (nas palavras de Lilian Pacce, "quais os aplicativos preferidos dos fashionistas"), como se pode observar no trecho abaixo:

Lilian Pacce: [...] Em março, o GNT Fashion também vai vir cheio de novidades. Vocês não podem perder. Celular hoje, gente, não serve só para telefonar e mandar mensagens, não. Dá para twittar, fazer fotos, acessar o Facebook, falar no Skype e usar vários recursos. A gente foi ver quais são os aplicativos preferidos dos fashionistas.

\footnotetext{
${ }^{3}$ Gisele Bundchen foi questionada por Lilian Pacce a respeito da declaração dada durante o lançamento de sua linha de produtos de beleza sobre o fato de que não usava nem recomendava o uso de protetores solares. $\mathrm{Na}$ entrevista, a modelo tenta explicar e amenizar o contexto da declaração dada anteriormente.
} 
Nem sempre, no entanto, os entrevistados reforçavam a associação entre o público de moda ("moderninho" ou "fashionista", nas palavras das apresentadoras) e o uso de novas tecnologias. Algumas entrevistadas, como a atriz Carolina Ferraz, afirmaram nunca usar Facebook e checar apenas emails no celular. Mesmo assim, o programa continuou enfatizando o uso dos recursos tecnológicos como forma de identificação com o mundo da moda. Além disso, reforçou seu próprio pertencimento a este mundo (jovem, inovador, etc), ao anunciar tais recursos como forma de interatividade com a sua audiência:

Lilian Pacce: Olha, o GNT também tem um aplicativo para iPhone e iPad bem bacana. É um guia de looks com fotos do que as pessoas estão usando nas ruas do mundo todo. O usuário também pode enviar fotos, criar seu próprio armário virtual e compartilhar suas imagens preferidas. E o melhor: o lookbook GNT é de graça. E vocês? Também estão super cheios de aplicativos? Eu tenho um monte no meu celular. E vocês? (dirigindo-se aos comentaristas).

Ao longo do tempo, as apresentadoras também reforçaram o uso de blogs e sites vinculados ao programa. Além de buscar uma associação com as novas tecnologias, as edições especiais do GNT Fashion foram marcadas pela auto-referência. Várias vezes, as apresentadoras repetiram informações sobre o canal, outros programas de comportamento, como o Saia Justa, um talk show voltado para o público feminino, e ainda anunciaram uma nova atração capitaneada pela ex-modelo Mariana Weickert.

É importante destacar que as duas edições também foram marcadas pela ênfase na relação entre os eventos e as cidades que os receberam. A associação entre o evento e a cidade mostrou uma busca por uma identidade brasileira e local (no caso, carioca e paulista), que distinguiria a moda brasileira da produzida "lá fora" (isto é, no exterior). Isso foi mais perceptível na edição do Rio de Janeiro, como pode ser observado na descrição que a apresentadora Lilian Pacce faz do evento, que tentou mostrar "a alma carioca":

Lilian Pacce: Nesta edição, o cenário do Fashion Rio mostra pessoas que colaboraram com a construção da identidade do Rio de Janeiro, como modelos e estilistas desde os anos 70. O título é "Alma Carioca" e uma ala inteira é dedicada à estilista Zuzu Angel, que se destacou com a proposta bem brasileira no período da ditadura no país.

Hildegard Angel (jornalista e filha de Zuzu Angel): Só pela área externa, essa quantidade de ampliações de fotos lindas, que caracterizam o período, que caracterizam a alma da moda carioca. Só isso aqui eu já estou realmente muito comovida. 
Nas duas edições do programa, o que é narrado como "identidade brasileira" são representações de um imaginário social localizado nas cidades do Rio de Janeiro e de São Paulo e que de forma alguma contemplam a heterogeneidade nacional. Essa identidade brasileira (carioca e paulista), ao mesmo tempo, foi recorrentemente confrontada com as referências externas. Durante a maior parte dos comentários, o trabalho dos estilistas brasileiros foi analisado a partir de suas influências, seja da própria moda, seja do universo cultural mais amplo que compreende a indústria da mídia. Isto pode ser observado no desfile de André Lima, em São Paulo, identificado como seguidor do francês Yves Saint Laurent (como o próprio Lima reconheceu), e no desfile de Ana Magalhães. A estilista da marca Maria Bonita Extra produziu uma coleção inspirada no universo da dança e foi inquirida a respeito da similaridade de sua proposta com a estética do filme norte-americano Cisne Negro, vencedor do Oscar em 2011. Neste caso, Magalhães refutou a influência, declarando ser apenas uma coincidência feliz. Nos dois casos as comparações parecem tentativas de legitimar o trabalho dos estilistas brasileiros a partir de referências estrangeiras, e isso complexifica a relação entre a produção nacional e a internacional (tanto a produção de moda focada no trabalho do estilista-criador quanto a produção sobre a moda a partir do conteúdo jornalístico e midiático).

É a partir deste contexto - da própria organização do programa e do estabelecimento de relações com outros valores subjacentes à cultura e à moda - que se constituíram os enquadramentos dominantes nas edições do GNT Fashion.

\section{As bandeiras da República Cavalera}

O desfile da Cavalera descrito no parágrafo de abertura deste artigo é a porta de entrada para esta discussão por ser representativo para refletir sobre as dinâmicas aqui propostas. Evidencia, na própria materialidade das roupas desta coleção, um valor político que é esteticizado em camisetas, vestidos, calças, agasalhos e diversas outras peças. Isso se desdobra em um valor simbólico, que por sua vez constitui a própria identidade da marca. Em entrevista ao GNT Fashion, os estilistas definem o conceito da "República Federativa Cavalera" da seguinte forma: 
Fabiano Grassi: A gente fez o brasão da República Cavalera. Então, ele aparece no desfile inteiro e, depois, ele vai entrar todo multicortado, como se fosse uma estampa corrida.

Igor de Barros: A ideia das bandeiras, que a gente já vem trabalhando e agora a bandeira, ela é construída, ela dá o volume da roupa, ela forma... Com o dançar da bandeira no ar a gente desenhou essas peças. Na estampa que mistura os patchworks com a bandeira de São Paulo e do Brasil, os patchworks com o brasão, enfim. [...]

Fabiano Grassi: O look da Cris S. que vem o brasão mesmo, é uma camiseta off-white, que é a camiseta ícone da coleção. Ela é toda desconstruída, toda lavada, toda puída e ela tá com o brasão, uma camiseta off-white, é um look lindo. Aí, ela tá embaixo com um vestidinho que já é esse brasão todo desconstruído, todo estampado em seda também.

Igor de Barros: É um brasão que vem para ficar na marca. A gente está carimbando aqui essa República Cavalera. [...] É o nascimento aqui.

A palavra "mistura", que aparece na fala de Igor de Barros, é significativa para pensar os imperativos que direcionam as lógicas da coleção, desde a concepção da ideia-tema, passando pela produção material das roupas na fábrica e pela produção simbólica de um discurso que culmina com a apresentação do desfile e reverbera nos meios de comunicação, mas não se esgota aí - considerando que a produção de sentido é processual, contínua e envolve cada vez mais atores nas interações sociais cotidianas (APPADURAI, 1999).

Essa "mistura" se estabelece, pois, em instâncias variadas e de forma análoga à mistura de que fala Marcel Mauss no Esboço de uma Teoria Geral sobre a Magia [2007 (1902-03)] e no Ensaio sobre a Dádiva [2007 (1923-24)]. Para aprofundar a compreensão dessa equação, a noção de fato social total apresentada por Mauss é fundamental:

Existe aí um enorme conjunto de fatos. E fatos que são muito complexos. Neles, tudo se mistura [...]. Nesses fenômenos sociais "totais", como nos propomos a chamá-los, exprimem-se, de uma só vez, as mais diversas instituições: religiosas, jurídicas e morais - estas sendo políticas e familiares ao mesmo tempo -; econômicas - estas supondo formas particulares da produção e do consumo, ou melhor, do fornecimento e da distribuição -; sem contar os fenômenos estéticos em que resultam esses fatos e os fenômenos morfológicos que essas instituições manifestam. (2007, p. 187)

Os fatos sociais totais são assim definidos porque constituem sistemas sociais inteiros que mobilizam a totalidade da sociedade e das suas instituições. Em comum com Durkheim (1995), Mauss enfatiza a importância das instituições para a compreensão dos princípios econômicos. No entanto, radicaliza a concepção de sociedade como uma organização 
articulada por símbolos - de tal forma que se para Durkheim os fatos sociais devem ser tratados como "coisas", por serem exteriores aos indivíduos, para Mauss os fatos sociais são totais porque também são "símbolos" (MARTINELI, 2011). A moda no contexto estudado neste artigo (e como vivenciamos hoje) pode ser considerada um fato social total pois afeta (e é afetada por) diversas instâncias da vida, como o consumo, o trabalho, o mercado, os sistemas jurídicos, a cultura, a política, a religião, a mídia. Trata-se de um sistema de produção de bens culturais inscrito em sistemas sociais mais amplos.

Mauss não se dedica especificamente ao estudo da moda, mas as categorias analíticas que propõe são úteis para refletir, em conjunto com o enquadramento, sobre esse fenômeno social. A "magia" da moda é a construção contínua do valor simbólico da marca, que é reproduzido, amplificado e recriado através dos enquadramentos que a mídia constrói sobre o tema e que, por sua vez, têm seus sentidos novamente recriados e transformados pela audiência. Essa dinâmica possui um papel fundamental na própria estruturação material e social do sistema (MILLER, 1987, 1998, 2007; KÜCHLER; MILLER, 2006; MARTINELI, 2007, 2009, 2011). Envolve instituições, indivíduos, sentimentos, coisas, valores, contratos, obrigações, liberdades e constrangimentos, e constitui, entre esses múltiplos atores, relações que não são nunca equivalentes (no sentido de um equilíbrio simétrico), mas sempre desiguais, pois a própria "harmonia" do sistema depende de um "equilíbrio instável". Isso implica conceber as disputas, os conflitos e a multiplicidade de vozes como irremediavelmente constitutivos do mundo da moda - o que, por sua vez, insere a política no debate (SANTA CRUZ; MARTINELI; MACHADO, 2009).

Durante a exibição ao vivo do desfile da Cavalera, a apresentadora do GNT Fashion protagoniza um episódio que também referenda a afirmação de que a "mistura" se dá em diversos níveis. Lilian Pacce introduz uma declaração que parece ser uma (des)continuidade do pensamento dos estilistas, transcrito mais acima, sobre a juventude brasileira. Trata-se de uma fala atribuída a eles, mas que não foi dita em frente às cameras e se torna pública quando Pacce revela, em cadeia nacional, a informação de bastidores:

Os meninos [estilistas Fabiano Grassi e Igor de Barros] estavam me falando, antes do desfile, que eles ficaram um pouco chateados como o jovem do Brasil anda meio alheio enquanto, enfim, na Inglaterra tem protesto disso; na França, daquilo. Bom, agora no Egito nem se fala, o que está acontecendo... Será que o Brasil não devia também ter mais...? 
A opinião dos estilistas, descrita e endossada por Lilian Pacce, parece ser uma fala dita no contexto de uma conversa pessoal, não de entrevista, e revela um certo desencantamento com "os jovens brasileiros". Curiosamente, isso vem a público enquanto o desfile acontece, é transmitido ao vivo pelo GNT Fashion e esteticamente apresentado como uma celebração da juventude. A própria Pacce, na sequência, tece um comentário que acompanha a observação do editor de moda Paulo Martinez e do estilista André Lima, que assistem com ela e comentam, no estúdio do programa, o desfile da "República Cavalera":

Paulo Martinez: A gente viu um monte de releitura de [jaquetas] perfecto.

Lilian Pacce: Um monte. Eu adoro perfecto.

Paulo Martinez: Eu também. É um clássico.

Lilian Pacce: Um clássico que veste tão bem em todo mundo.

André Lima: A gente se sente logo tipo o contestador, o selvagem. É espumal (sic). Eu adoro.

Lilian Pacce: E esse é um papel que a Cavalera realmente tem que desempenhar aqui, tem essa função. No dia que ela não fizer isso, a gente vai ficar meio decepcionado.

É sintomático perceber como a apresentadora também situa, ela mesma, os jovens brasileiros quase como apáticos - termo inclusive utilizado por André Lima para definir a relação da juventude brasileira com o país. Lima, por sua vez, chega a essa "conclusão" logo após Lilian Pacce referendar publicamente a conversa de bastidores com os estilistas da Cavalera. O estilista prossegue com comentários que reiteram essa opinião e chega a comparar jovens brasileiros e ingleses em função do uso que fazem das cores das bandeiras dos respectivos países em suas roupas. O editor de moda Paulo Martinez e o maquiador Marcos Costa, também presentes no estúdio do programa, além da própria Pacce, entram no debate, que transcorre em torno do consenso coletivo/acusatório de que o jovem brasileiro não só é "apático", como também cultiva uma euforia pela cultura estrangeira dos países centrais do ocidente - representada neste diálogo pela bandeira -, enquanto se envergonha das cores locais (exceção apontada quando as roupas são camisas de futebol - isto, sim, motivo de orgulho e paixão nacional):

André Lima: Engraçado. O jovem brasileiro é apático.

Paulo Martinez: Eu acho que esses ícones que a gente têm aqui no Brasil, que eles também têm lá fora, por exemplo, o uso da bandeira inglesa, o uso da bandeira americana, os jovens usam muito. A gente - brasileiro - até usa camiseta com a bandeira da Inglaterra, mas aí quando a gente faz uma bandeira do Brasil as pessoas não gostam, a gente tem medo do verde e amarelo. É mais bonito terminar o desfile com verde e amarelo. 
André Lima: Engraçado. Verde e amarelo é a bandeira do Brasil, então está errado.

Paulo Martinez: Pois é. E aí a gente não gosta, as pessoas não gostam.

Marcos Costa: Mas vocês não acham que as pessoas usam mais a camiseta da seleção brasileira aqui no Brasil?

Lilian Pacce: É. A camiseta da seleção tem mais valor do que a bandeira.

Marcos Costa: É uma outra relação.

André Lima: É a relação com o futebol, é diferente. Mas essa coisa da apatia do jovem eu acho muito chocante.

Esse enquadramento parece sinalizar mais para uma reificação do jovem brasileiro, do que para uma tentativa de resgate da identidade juvenil que a jornalista e os especialistas consideram "perdida" e em relação à qual se mostram, ao menos retoricamente, nostálgicos. Sinaliza também para uma possibilidade de enquadramento da coleção da "República Federativa Cavalera" como a própria materialização desse desencantamento expresso em suas narrativas. $\mathrm{O}$ que Pacce oferece como justificativa para esse enquadramento que aponta a falta de engajamento do jovem brasileiro são referências de ação política ou em países europeus ou no Egito, que naquele momento era manchete nos jornais do mundo em virtude das manifestações populares para depor o ditador Hosni Mubarak, há mais de 30 anos no poder ${ }^{4}$.

O significado do discurso "político" sui generis da Cavalera - e da apresentadora do GNT Fashion e seus convidados - chama a atenção pela forma como a própria política é enquadrada de forma apolítica - por exemplo, aparentemente sem nenhuma relação com eleição e recente posse da nova presidenta de nosso país.

Finalmente, cabe retomar a ideia de mistura para pensá-la também metaforicamente. O desfile aconteceu ao som de um remix de O Guarani e Smells Like Teen Spirit, uma "mistura" musical que conduz à interpretação da coleção, também ela, como um remix: da política com a estética, da arte com a moda, da identidade nacional com a identidade da marca, das subculturas juvenis com as "liberdades" do mercado, da esfera pública com a governança corporativa, da cidadania com o consumo.

\section{Explicadores da moda: "O dourado é o novo preto"}

Se um enquadramento guia a representação da realidade, como mostrou Goffman

\footnotetext{
${ }^{4}$ Com exceção da França, os outros países citados como exemplos mobilização política da juventude nada têm de republicanos. Mesmo a França é mencionada en passant, pois naquele momento não havia algo do porte do que acontecia no Egito acontecendo nas ruas daquele país.
} 
(1985), a própria realidade, ao ser representada, é inerentemente constituída por partes selecionadas, isto é, por visões enfatizadas por quem conta a narrativa sobre o mundo. E no papel de narradores da realidade do mundo, os jornalistas e os chamados especialistas teriam o poder de influenciar como pensamos sobre os mais diversos assuntos do dia-a-dia (GUAZINA, 2011).

Como é possível observar acima no enquadramento do desfile da Cavalera, ao participar de um programa de televisão, o apresentador, repórter ou especialista torna-se um explicador ou narrador da própria realidade narrada e enquadrada, fornecendo chavesexplicativas para o entendimento do mundo de uma maneira quase pedagógica. Esta condição, inclusive, é defendida explicitamente por jornalistas da Rede Globo de Televisão (GUAZINA, 2011).

Alguns autores, como Aldé (2004), por exemplo, apontam que a condição de explicadores é, inclusive, percebida pelo cidadão comum, na medida em que a audiência identifica o jornalista de televisão como alguém que pertence a uma "elite cognitiva", especialmente habilitada para formar a opinião dos demais por saber mais sobre o assunto, notadamente por aqueles que se consideram ignorantes ou desinformados em relação à política

Esta condição também se aplica à cobertura de moda. Fica evidente para um observador atento que os narradores (apresentadores e comentaristas) se esforçam para explicar o que seriam a moda e o universo fashion para a audiência. Ao fazerem isso, organizam os acontecimentos de forma a enfatizar um sentido (valores), ao mesmo tempo em que delimitam o território dos que sabem (os especialistas) dos que não sabem (a audiência) mas que querem saber para pertencer a este mundo.

Um dos indicadores da "opinião autorizada" sobre os eventos está na descrição feita no site do canal GNT sobre a própria jornalista-apresentadora Lilian Pacce ${ }^{5}$. Lá ela é apresentada como uma das maiores autoridades em moda no país. E, como tal, comporta-se perante as câmeras, como no trecho a seguir, que se passa durante a edição sobre o Fashion Rio:

Lilian Pacce: (...) Alguns estão dizendo que eu estou provando que o dourado é o novo preto. Quem sabe, não é?

Flavia Pommianosky: Adorei. O dourado é o novo preto.

\footnotetext{
${ }^{5}$ Compreendida aqui cf. explica Aldé (2004). 
A fala de Pacce transcrita acima é um comentário a respeito de um tweet da audiência que elogiava sua roupa: uma camiseta com o famoso ícone Smiles estampado em tamanho grande e cor dourada. Nesse momento específico a autoridade da jornalista a respeito da moda é duplamente endossada, tanto pelo seu repertório quanto pelo seu guarda-roupas.

Em vários momentos, os comentaristas também deixam transparecer seu papel de explicadores do mundo da moda, inclusive para os jornalistas que cobrem os eventos e que não fazem parte do programa. Esse enquadramento se faz presente em comentários como o de Paulo Martinez na edição de São Paulo, quando o editor de moda afirma que "o jornalista está na hora de aprender a ler desfile" (sic), e ainda nas explicações detalhadas das nomenclaturas utilizadas para identificar padrões de moda. Neste caso, um exemplo é o comentário do estilista da Colcci, Jeziel Moraes, que explica como foi fazer a coleção de inverno da marca para chegar em um resultado que seria "o que a gente chama nos blogs de moda de streetwear". Por fim, os especialistas falam ainda mais abertamente sobre sua autoridade, uma vez que, novamente nas palavras de Martinez, "a gente tem mais tarimba de ver o desfile".

Este enquadramento pode ser percebido também na fala da ex-modelo e atual apresentadora de TV Mariana Weickert sobre seu novo programa que pretende, segundo ela, "desmistificar o mundo da moda [...] para as pessoas entenderem com um pouquinho mais de facilidade":

Lilian Pacce: (...) Mas conta um pouquinho mais. Como vai ser o programa? Mariana Weickert: Então, é um programa de moda, mas vai rolar umas dicas de estilo, de comportamento, vai entrar um pouquinho de arquitetura, um pouquinho de culinária, um pouquinho de coisa que a gente gosta. Vai ter muito serviço, vai ter muitas dicas. A gente vai meio que desmistificar o mundo da moda. Interpretar isso que a gente vem mostrando aqui no São Paulo Fashion Week para as pessoas entenderem com um pouquinho mais de facilidade. E eu estou super empolgada.

E se as apresentadoras, comentaristas e jornalistas, ao assumirem o papel de narradores, têm a atribuição de mostrar e esclarecer o que é moda para a audiência, os estilistas e outros profissionais como os maquiadores, paradoxalmente, se definem como artistas que não precisam se explicar - uma vez que seriam livres para fazer o que quiserem. Esta ambiguidade do criador em contraposição ao narrador fica evidente no diálogo entre o estilista André Lima e a apresentadora Lilian Pacce sobre a coleção do estilista mostrada momentos antes: 
Lilian Pacce: (...) De volta aqui, ao vivo, do São Paulo Fashion Week com o editor de moda Paulo Martinez, o maquiador Marcos Costa e o estilista André Lima, que acabou de mostrar a sua coleção e está aqui para comentar com a gente. André, eu estava lendo o teu release, assim, muito prolixo. Queria entender qual foi o ponto de partida da coleção.

André Lima: Na verdade, a intenção é essa mesmo. Eu detesto release, eu detesto explicar coleção. Eu acho que é interessante que as pessoas tenham a leitura delas e adoro quando elas não gostam. Eu acho que é um direito. Justamente, eu chamo Logullo. [o release foi escrito a partir do trabalho de um escrito]

Lilian Pacce: Eduardo Logullo.

André Lima: Eu acho ele um grande escritor. Na verdade, eu nem acho que é prolixo. Eu acho que ele realmente dá voltas porque a intenção é não dar pistas claras e dizer "a cor foi essa, o tema foi aquele". Então, quando vêm me perguntar no backstage qual foi o tema, eu tenho vontade de empurrar.

Lilian Pacce: Ai, gente, jornalista sofre porque tem que passar uma informação.

André Lima: Eu detesto.

Paulo Martinez: Mas o jornalista está na hora de aprender a ver o desfile e o texto do Logullo é maravilhoso.

Estilista/André Lima: Na verdade, eu não tenho uma ideia base. Eu começo a juntar ideias e eu gosto quando as ideias são até caóticas e contraditórias, porque eu acho que aí o meu trabalho vem, de tentar juntar.

Apresentadora/Lilian Pacce: Então, vamos chamar o desfile e rodar o VT para você contar como é esse processo então.

No trecho acima fica explícito que, apesar da apresentadora e dos especialistas compartilharem o status de "autoridades da moda", os lugares de fala que cada um ocupa são distintos em função de seus trabalhos. Se incluirmos nesse enquadramento a audiência, que nessas edições do GNT Fashion tem voz através dos tweets que são selecionados pela produção do programa e aparecem na tela como lettering em momentos esporádicos, podemos considerer aí uma dinâmica que conforma hierarquias de credibilidade no sentido de Becker (2007). A esse respeito o sociólogo norte-americano afirma que

Em qualquer sistema de grupos hierarquizados, os participantes dão por certo que os membros do grupo mais elevado têm o direito de definir o modo como as coisas realmente são. Em qualquer organização, não importa o que seu organograma mostra, as setas que indicam o fluxo da informação apontam para cima, demonstrando assim (ao menos formalmente) que os que estão em cima têm acesso a um quadro mais completo do que se passa que os de qualquer outro nível. Membros de grupos inferiores terão informação incompleta e, em consequência, sua visão da realidade será parcial e distorcida. Portanto, do ponto de vista de um participante bem socializado com o sistema, qualquer história contada pelos de cima é intrinsecamente merecedora de ser vista como a descrição mais digna de crédito obtenível sobre o funcionamento da organização. E uma vez que, 
como Sumner mostrou, questões de posição hierárquica e status estão contidas nos usos e costumes, essa crença tem uma qualidade moral. Sentimo-nos, se formos membros adequados do grupo, moralmente obrigados a aceitar a definição imposta à realidade por um superior, de preferência àquela esposada por subordinados. (Por analogia, o mesmo raciocínio se aplica às classes sociais de uma comunidade.) Assim, a credibilidade e o direito de ser ouvido são diferencialmente distribuídos pelos níveis do sistema. (BECKER, 2007, p. 123)

Apesar do público do programa ser classificado como quem "não entende" a moda, paradoxalmente é na cultura de massa que constitui o repertório de grande parte dessa audiência que muitos estilistas, maquiadores, editores, fotógrafos, cabeleireiros buscam referências para o seu trabalho. O fato dos programas serem transmitidos em canal pago suporia uma segmentação dos interesses da audiência em relação à diversidade de opções e, consequentemente, uma maior identificação de quem assiste aos programas com o universo da moda (isto é, assiste quem compartilha interesse). No entanto, o discurso da apresentadora e dos especialistas pressupõe um distanciamente entre a elite produtora de moda (ou de discursos sobre a moda) e os consumidores.

Esse repertório familiar ao público, no entanto, é re-significado material e simbolicamente a cada nova temporada de desfiles, às vezes de forma quase onírica, e isso é o que muitas vezes desperta o desejo de consumo. André Lima dá pistas a esse respeito quando, fazendo um balanço de seu próprio desfile em São Paulo, afirma que o papel do estilista é fazer as mulheres sonharem (e isso, por sua vez, remete à "magia" da moda mencionada anteriormente):

André Lima: Engraçado. Vai mudando e você vai vendo um pouco do papel. $\mathrm{Eu}$ acho que o papel é fazer as pessoas sonharem, as mulheres sonharem. E acho que dá para convencer uma mulher a usar uma roupa dessas. É meio difícil.

Lilian Pacce: Também acho. Pode até ser. Pensando bem, eu não acho.

André Lima: Eu acho um pouco. Aqui eu acho.

Ainda no diálogo, curiosamente, a roupa perde importância diante do talento, mas a experiência de moda é recuperada logo em seguida na argumentação do estilista:

Paulo Martinez: Se você tem talento, não importa a roupa que você está usando.

André Lima: Não, não é isso. Não é que eu acho que tem que andar aparamentado, mas também é uma experiência para quem está fazendo a 
roupa, para quem está comprando a roupa, a relação com o estilista. Eu acho que isso é básico. Eu gosto de me apresentar assim.

Lilian Pacce: Você tem gostado na vida também com essa coisa mais...

André Lima: É, mudei.

Lilian Pacce: Ainda bem.

André Lima: Graças a Deus.

Com essa postura André Lima assume, no programa, uma dupla condição. Se, por um lado, considera-se criador - representante, portanto, de uma subcultura (BURKE, 2000) característica de um grupo específico - também desempenha, com a autoridade que lhe concede ser um criador - o papel de narrador sobre moda. No entanto, ao contrário da apresentadora Lilian Pacce, que é jornalista e tem a preocupação de explicar para a audiência o que se passa nos desfiles como uma característica expressamente fundamental, Lima mostra as contradições subjacentes deste jogo.

Se o espaço televisivo dos explicadores do mundo da moda se preocupa em esclarecer e "desmistificar" esse universo, a própria moda também é, ironicamente, enquadrada aí como arte.

\section{Thinking outside the box: moda como arte}

A percepção da moda como arte, ignorando toda a estrutura da indústria da qual faz parte e os interesses comerciais, caracteriza este enquadramento que expressa uma exaltação das liberdades criativas. Aqui, é possível perceber como estilistas e outros criadores são mostrados como artistas livres para criar o que quiserem, sem amarras. Um exemplo está no seguinte trecho do GNT Fashion da semana de moda do Rio de Janeiro.

Lilian Pacce: [...] O estilista pernambucano Melk Z-Da foi o destaque do primeiro dia do Fashion Rio. O Melk tem um trabalho bem autoral e está sempre propondo novos materiais. Dessa vez, ele mistura tapete de banheiro com cabelos. Tapete de banheiro com cabelo, Flavia.

Flavia Pommianosky: É, aquelas maluquices que o Melk faz, mas funciona, surpreende a gente. Eu acho que ele tem essa coisa de matéria-prima, de pesquisar e sempre é uma imagem de moda bacana.

Lilian Pacce: Leo, você acha tudo isso uma loucura?

Leo Jaime: É interessante. Eu fico curioso. Eu acho que essa liberdade de criar, imaginar, pensar fora da casinha, pensar fora da caixinha, "think outside of the box" como se diz nos Estados Unidos. É muito interessante, é difícil escolher alguma coisa porque você, de repente, pode tudo. 
Pensar "fora da caixa" também é enfatizado como valor característico da moda e do comportamento apresentados nos desfiles, ainda que, curiosamente, seja uma moda para consumo de massa no país, adaptada ao objetivo primordial de reprodução comercial (as semanas de moda do Brasil e o próprio GNT Fashion privilegiam o prêt-à-porter) - e a um comportamento que, se aponta para escolha individual, restringe a liberdade pelo consumo. Um exemplo deste enquadramento pode ser observado no diálogo sobre o uso da sombra amarela pelas mulheres, proposto no desfile da marca Cavalera:

Lilian Pacce: Eles estavam me falando que eles procuram sempre manter essa coisa da individualidade. Cada modelo tem um make, um cabelo diferente. É legal isso.

Marcos Costa: Tem boca pink, sombra dourada, sombra azul.

Lilian Pacce: Sombra amarela. Sombra amarela é difícil. Ou não?

Marcos Costa: É difícil.

Lilian Pacce: Para a vida?

Marcos Costa: Depende. Não tem muito isso, Lilian. Depende da pessoa que vai usar. Eu acho que ele faz isso muito bem e eu acho que, dentro do contexto da Cavalera, eu acho que fica bem bacana. O que você acha, Paulo? Paulo Martinez: Eu acho que, para a vida real, sobre o amarelo, é jogo duro. Marcos Costa: Gente, para que vida real?

Lilian Pacce: Vamos falar da passarela. É porque as pessoas acham que tudo que está aqui elas têm que usar. Não tem que usar.

Paulo Martinez: Não necessariamente.

André Lima: Ela vai usar se ela quiser usar. Ela vai segurar a onda se ela segurar.

Marcos Costa: Mas tem muita gente que pergunta sobre isso. "Ah, eu posso usar sombra amarela?" Depende da pessoa, depende da personalidade da pessoa, para o lugar que ela vai e do espelho que ela tem em casa.

André Lima: Gente, eu não tenho saco para regra. Ah, se eu tenho que usar, posso usar aquilo, conselho de moda eu acho a coisa mais cafona do mundo.

Paulo Martinez: Receita não dá.

André Lima: Não dá.

Paulo Martinez: A gente briga tanto para a moda ficar democrática.

Novamente um valor político é evocado para enquadrar narrativas sobre a liberdade de escolha no mundo da moda. Trata-se de um discurso que compatibiliza os ideais do liberalismo de mercado com liberdade, democracia e até cidadania, localizando as práticas de consumo como espaço privilegiado para o exercício de liberdades tradicionalmente associadas à esfera pública. Mas, se dar receita sobre o que usar não cabe aos especialistas de moda enquanto criadores - cabe, sim, aos explicadores do mundo da moda, como fica claro na sequência:

André Lima: E a gente, estilista, quer ser inspirar na loucura dos outros. Então, errem! 
Lilian Pacce: Errem! Esse conselho é muito bom, o do André.

Ora, o próprio aconselhamento ao "erro" contém em si um julgamento de valor que parte de um lugar de fala específico e, em última instância, também constitui uma condição de legitimação e de produção da moda como discurso e como cultura material. A chave para o entendimento dessa condição de produção - que é também um processo de re-produção - é, literalmente, a mágica. Bourdieu e Delsaut (2002) também situam as operações simbólicas de criação na moda de forma análoga à crença na magia: é preciso ter fé na raridade da marca, no nome do criador. Embora os autores se detenham especificamente na produção de luxo na moda de alta costura na França no início dos anos 1970, sua reflexão é emblemática para pensar outros níveis de produção considerando que, atualmente, os processos de distinção social através da moda operam em outros eixos. Quando Simmel (1957), um dos pioneiros a falar da distinção como forma de diferenciação social a partir dos usos de peças de vestuário, reflete sobre dinâmicas de classes no tecido social a partir de uma análise cultural da moda e sua relação com a modernidade, vincula moda e imitação como fenômenos indissociáveis. Para o sociólogo alemão, a moda é uma forma de imitação e equalização social que, paradoxalmente, possui uma dinâmica de transformação constante, de maneira que ao mesmo tempo em que equaliza socialmente indivíduos de uma classe, segrega outros estratos sociais (p. 543). Para Simmel, as modas são sempre modas de classe (p. 543) porque as classes superiores se distinguem das classes mais baixas pelo uso de "suas" modas, que são imediatamente abandonadas e recriadas no instante em que estas classes mais baixas delas se apropriam (p. 543-544) ${ }^{6}$. Atualmente, contudo, é possível considerar uma nova dinâmica no modo de difusão da moda, de forma que as expectativas dos indivíduos consumidores não necessariamente se enquadram em convenções de classe. Cada vez mais, os desejos são mobilizados no sentido de valorizar a expressão individual e isso reflete uma dinâmica de distinção na moda mais focada em cultura de grupo do que em classes sociais - de modo que grupos tradicionalmente periféricos, como jovens, punks, office boys, entre outros, hoje fazem e influenciam a moda (que, em função disso, reivindica para si o estatuto de "democrática").

\footnotetext{
${ }^{6}$ A essa teoria, que revela uma perspectiva histórica mas necessita um maior refinamento metodológico para o estudo da moda contemporânea, dá-se o nome de trickle-down ${ }^{6}$. A teoria ou efeito trickle-down destaca que esse processo de imitação é contínuo e progressivo, e ao mesmo tempo que revela uma disputa social, descortina também um comportamento provocativo entre as classes. No pensamento simmeliano, isso seria o que produz mudanças constantes e faz da inovação o motor fundamental da moda.
} 
É importante demarcar que essas produções acontecem, na grande indústria da moda, de forma estilizada e quase "mágica", pois realizar uma crítica social seria trazer à tona as próprias contradições internas desse sistema.

É perceptível como a construção da magia na moda passa fortemente pela mídia. Para mencionar um episódio histórico, basta relembrar que foi uma editora da Harper's Bazaar quem batizou o new look de Christian Dior ${ }^{7}$; e que quando Mauss pergunta, ao final de seu Esboço sobre uma Teoria Geral da Magia (2007), “onde está o equivalente (à magia) em nossa sociedade", Bourdieu (2003, p. 206), algumas décadas mais tarde, lhe responde: "Eu gostaria de mostrar que é preciso procurar este equivalente em Elle ou no Le Monde (especialmente na página literária)" (MARTINELI, 2011).

A re-produção da magia da moda nos meios de comunicação se dá em duas principais instâncias discursivas: na publicidade e no jornalismo - sendo que esta última, por ser "notícia", possui maior aderência e credibilidade. Isso acontece ainda que um editorial de moda não seja muito distinto, em seu conteúdo, de um anúncio publicitário, e perpetue a mistificação da marca num sentido semelhante. Revistas internacionais como Elle, Vogue e a própria Harper's Bazaar seguem essa lógica - sem falar em inúmeros blogs e programas de televisão, como é o caso do GNT Fashion. Muitas vezes o sucesso do conteúdo veiculado depende dessa racionalidade, daí não ser ao acaso a afirmação de Bourdieu (2003, p. 214) de que "para jogar este jogo, é preciso acreditar na ideologia da criação e, quando se é jornalista de moda, não é bom ter uma visão sociológica da moda” (MARTINELI, 2011).

\section{Encerramento do desfile}

No percurso deste estudo exploratório, pudemos mostrar como se constituem os enquadramentos dominantes do programa GNT Fashion nas duas edições dedicadas às semanas de moda de outono-inverno no Rio de Janeiro e em São Paulo em 2011. Compreender o conceito de enquadramento a partir dos princípios de organização apontados por Goffman (1986) permitiu identificar algumas das ideias que predominaram nas narrativas sobre a moda.

\footnotetext{
${ }^{7}$ Originalmente batizada de Corolle, essa coleção se tornou mundialmente conhecida como o new look quando Carmel Snow, então editora da revista norte-americana Harper's Bazaar, assim definiu o estilo lançado por Dior: "It's quite a revelation dear Christian. [...] Your dresses have such a new look!" (MARTINELI, 2011).
} 
Foi possível observar, ao longo deste catwalk eletrônico, como o desfile de uma marca - a "República Federativa Cavalera" - acionou uma mistura de elementos da política, da estética e da juventude, que possibilitaram (1) um julgamento por parte dos participantes do programa sobre a atuação política da juventude brasileira e (2) uma nova proposta de engajamento político intermediado pelo objeto de consumo.

Também pudemos identificar como os comentaristas e apresentadores desempenharam um papel quase pedagógico ao explicar e narrar o mundo da moda para a audiência. Além disso, a própria moda foi enquadrada como arte ao se enfatizar seu aspecto de liberdade criativa, ao mesmo tempo em que isso, quando dito, ofuscou seu lugar fundamental dentro do processo de produção comercial.

Finalmente, é importante considerar que a propagação do discurso pela mídia também integra a "mistura" aqui problematizada, que se configura como uma (re)construção sem fim e não linear de sentidos. Embora o foco privilegiado deste artigo seja o programa GNT Fashion, é preciso levar em conta que os canais de divulgação de moda são mútiplos e interconectados, de forma que os discursos transitam simultaneamente em veículos tradicionais como a televisão, associada às novas plataformas digitais, que incluem site e blog da marca e também redes sociais - como é o caso do Twitter, usado ativamente pela audiência do GNT Fashion para interagir ao vivo com o programa.

Ao enquadrar, o programa GNT Fashion define o que é moda e as relações sociais que se conformam em torno dela. Assim, a produção de um discurso sobre a moda, a partir do trabalho dos jornalistas, bem como dos convidados - estilistas, maquiadores, cantores, celebridades - que se posicionam em um lugar de fala que os situa como autoridades, tem a pretensão de ensinar à audiência modos de enunciação social.

No caso específico do objeto aqui analisado, "trabalho" e "produção" implicam, pois, a redefinição de espaços e práticas para além da fábrica, e incluem os meios de comunicação, mais especificamente o programa GNT Fashion, do canal pago GNT, como referência para o consumo de moda - enquanto cultura material, simbólica e informação - em função de modelos de conduta que se renovam a cada temporada. 


\section{Referências}

ALDÉ, A. A construção da política. Rio de Janeiro, FGV Editora, 2004.

APPADURAI, A. Introduction: commodities and the politics of value. In: The Social Life of Things: commodities in cultural perspective. Cambridge: Cambridge University Press, 1999.

BECKER, H. Segredos e truques da pesquisa. Rio de Janeiro: Jorge Zahar Ed., 2007.

BOURDIEU, P. Alta Costura e Alta Cultura. In: BOURDIEU, Pierre. Questões de sociologia. Lisboa: Fim de Século, 2003.

; DELSAUT, Y. O Costureiro e Sua Grife. In: BOURDIEU, Pierre. A Produção da Crença: contribuição para uma economia dos bens simbólicos. São Paulo: Zouk, 2002. p. 113-190.

BURKE, P. História e Teoria Social. São Paulo, Editora Unesp, 2000.

- Modernidade, Cultura e Estilos de Vida. In: BUENO, Maria Lucia; CAMARGO, Luiz Octávio de Lima (orgs.). Cultura e Consumo: estilos de vida na contemporaneidade. São Paulo: Senac, 2008.

DOUGLAS, M.; ISHERWOOD, B. O Mundo dos Bens: para uma antropologia do consumo. Rio de Janeiro: Editora UFRJ, 2004.

DURKHEIM, E. As Regras do Método Sociológico. 15 ed. São Paulo: Companhia Editora Nacional, 1995.

ENTMAN, R. Framing: Toward Clarification of a Fractured Paradigm. Journal of Communication, Washington, v. 43, n. 4 (Autumm), p. 51-58, 1993.

GNT FASHION: Especial Fashion Rio inverno 2011.

Disponível em: http:/gnt.globo.com/gntfashion/Videos/_1409981.shtml Acessado em 18 jun 2012.

GNT FASHION: Especial São Paulo Fashion Week inverno 2011.

Disponível em: http://gnt.globo.com/gntfashion/Videos/_1426378.shtml

Acessado em 18 jun 2012.

GOFFMAN, E. Symbols of Class Status. The British Journal of Sociology, London, v. 2; n. 4; p. 294-304, dec. 1951.

Northeastern University Press, 1986.

. A Representação do Eu na Vida Cotidiana. 11 ed. Petrópolis: Vozes, 2003. 
GUAZINA, L. Em busca da credibilidade: a cobertura adversária do Jornal Nacional no Escândalo do Mensalão. Tese de doutorado, Programa de Pós-Graduação em Comunicação, Universidade de Brasília, 2011.

HALL, S. A Centralidade da Cultura: notas sobre as revoluções culturais do nosso tempo. UEBEL, R.; BUJES, M. I.; COSTA, M. V. (trad.). Santa Maria: UFSM / Departamento de Geografia, 2005.

Disponível em: http://www.ufrgs.br/neccso/word/texto_stuart_centralidadecultura.doc Acesso em: 18 jun 2012

KÜCHLER, S.; MILLER, D. Clothing as Material Culture. 2. ed. Oxford: Berg, 2006.

MARTINELI, F. Siga a Etiqueta: marcas na paisagem urbana, emblemas sociais no universo do consumo. XIII Congresso Brasileiro de Sociologia: desigualdade, diferença $e$ reconhecimento, Recife, 2007.

Disponível em: http://www.sbsociologia.com.br/portal/index.php?option=com_docman\&task=doc_download \&gid=191\&Itemid=171 Acesso em: 18 jun 2012

. Marcas de Transição: Comunicação, cultura e novos significados do consumo no (pós)-socialismo. Contracampo (UFF), v. 1, p. 1, 2009.

Disponível em: http://www.uff.br/contracampo/index.php/revista/article/viewArticle/13 Acesso em: 18 jun 2012

PIRATARIA S.A.: circulação de bens, pessoas e informação nas práticas de consumo. Rio de Janeiro, 2011. Tese (Doutorado em Comunicação e Cultura) - Escola de Comunicação, Universidade Federal do Rio de Janeiro, Rio de Janeiro, 2011.

MAUSS, M. Sociologia e Antropologia. 2 ed. São Paulo: Cosac \& Naify, 2007.

MILLER, D. Consumo como Cultura Material. In: Horizontes Antropológicos, ano 13, n. 28 (jul/dez 2007), p. 33-63. Porto Alegre: PPGAS / UFRGS, 2007.

(org.). Material Culture: why some things matter. London: UCL Press, 1998.

. Material Culture and Mass Consumption. Oxford: Basil Blackwell, 1987.

ROCHA, E.; BARROS, C. Cultura, mercado e bens simbólicos: notas para uma interpretação antropológica do consumo. In: TRAVANCAS, Isabel; FARIAS, Patrícia (orgs.). Antropologia e Comunicação. Rio de Janeiro: Garamond, 2003.

SANTA CRUZ, L.; MARTINELI, F.; MACHADO, M. Quando a Etiqueta Vira Bandeira: os sentidos da moda e do consumo socialmente engajados. III Encontro ESPM de Comunicação e Marketing. São Paulo: ESPM, mai. 2009. 
SIMMEL, G. Fashion. In: The American Journal of Sociology. New York, p. 541-558, May, 1957.

Original recebido em: 30/10/2012

Aceito para publicação em: 03/12/2012

\section{Resumo do autor}

Fernanda Martineli é professora Adjunta da Faculdade de Comunicação da UnB, doutora em Comunicação e Cultura pela Escola de Comunicação da UFRJ, pesquisadora do GEPCOR (Grupo de Estudos e Pesquisas em Comunicação Organizacional) e pesquisadora da CIEC (Coordenação Interdisciplinar de Estudos Contemporâneos).

Liziane Guazina é professora Adjunta da Faculdade de Comunicação da UnB, doutora em Comunicação pela Faculdade de Comunicação da UnB, pesquisadora do GEPCOR (Grupo de Estudos em Comunicação Organizacional) e pesquisadora do NEMP (Núcleo de Estudos Sobre Mídia e Política). 